\title{
BMJ Open Providing effective trauma care: the potential for service provider views to enhance the quality of care (qualitative study nested within a multicentre longitudinal quantitative study)
}

\author{
Kate Beckett, ${ }^{1}$ Sarah Earthy, ${ }^{2}$ Jude Sleney, ${ }^{2}$ Jo Barnes, ${ }^{3}$ Blerina Kellezi, ${ }^{4}$ \\ Marcus Barker, ${ }^{5}$ Julie Clarkson, ${ }^{6}$ Frank Coffey, ${ }^{7}$ Georgina Elder, ${ }^{8}$ Denise Kendrick, ${ }^{9}$ \\ The Impact of Injuries Study group
}

To cite: Beckett K, Earthy S, Sleney J, et al. Providing effective trauma care: the potential for service provider views to enhance the quality of care (qualitative study nested within a multicentre longitudinal quantitative study). BMJ Open 2014;4: e005668. doi:10.1136/ bmjopen-2014-005668

- Prepublication history for this paper is available online. To view these files please visit the journal online (http://dx.doi.org/10.1136/ bmjopen-2014-005668).

Received 9 May 2014 Revised 10 June 2014 Accepted 19 June 2014

CrossMark

For numbered affiliations see end of article.

Correspondence to

Professor Denise Kendrick; Denise.Kendrick@

Nottingham.ac.uk

\section{ABSTRACT}

Objective: To explore views of service providers caring for injured people on: the extent to which services meet patients' needs and their perspectives on factors contributing to any identified gaps in service provision.

Design: Qualitative study nested within a quantitative multicentre longitudinal study assessing longer term impact of unintentional injuries in working age adults. Sampling frame for service providers was based on patient-reported service use in the quantitative study, patient interviews and advice of previously injured lay research advisers. Service providers' views were elicited through semistructured interviews. Data were analysed using thematic analysis.

Setting: Participants were recruited from a range of settings and services in acute hospital trusts in four study centres (Bristol, Leicester, Nottingham and Surrey) and surrounding areas.

Participants: 40 service providers from a range of disciplines.

Results: Service providers described two distinct models of trauma care: an 'ideal' model, informed by professional knowledge of the impact of injury and awareness of best models of care, and a 'real' model based on the realities of National Health Service (NHS) practice. Participants' 'ideal' model was consistent with standards of high-quality effective trauma care and while there were examples of services meeting the ideal model, 'real' care could also be fragmented and inequitable with major gaps in provision. Service provider accounts provide evidence of comprehensive understanding of patients' needs, awareness of best practice, compassion and research but reveal significant organisational and resource barriers limiting implementation of knowledge in practice.

Conclusions: Service providers envisage an 'ideal' model of trauma care which is timely, equitable, effective and holistic, but this can differ from the care currently provided. Their experiences provide many suggestions for service improvements to bridge the

\section{Strengths and limitations of this study}

Qualitative study exploring service providers' perspectives on National Health Service (NHS) trauma care nested within a large UK multicentre mixed methods study of the impact of unintended injuries.

- Strengths include: a wide participant base from a range of settings and services in four diverse UK areas and interviews and analysis by researchers with a range of clinical and academic backgrounds.

- Contributes a unique perspective on NHS care generally and Trauma care in particular, identifies gaps and inequalities in current provision and explores means to improve the safety, effectiveness and experience of care.

- The main limitations are: does not include patient and carer perspectives to permit comparison with their experiences of care.

- Factors enabling some professions and individuals to sustain ideal care are not expanded on.

gap between 'real' and 'ideal' care. Using service provider views to inform service design and delivery could enhance the quality, patient experience and outcomes of care.

\section{INTRODUCTION}

Unintentional injury accounts for 11000 UK deaths $^{1}$ and more than 700000 hospital admissions in England per year. ${ }^{2}$ In the UK, 5.8 million people annually attend emergency departments (ED) following an unintentional injury. ${ }^{3}$ Working age adults comprise nearly $40 \%$ of unintentional injury deaths, $38 \%$ of hospital admissions and half 
of all ED attendances. ${ }^{3-5}$ Injuries are a leading cause of disability-adjusted life years lost, yet their impact and cost to the individual and society is frequently underestimated. ${ }^{6}$ A large and growing body of literature demonstrates that recovery can be prolonged and incomplete for many patients and suggests many socioeconomic, psychological and physical predictors of poorer outcomes. $^{7-10}$

The provision of the UK National Health Service (NHS) care for injured patients faces unprecedented challenges. ${ }^{11}$ Changes in patterns of injury and improvements in medical care have increased survival after injury and an ageing population places increasing demands on service provision. ${ }^{12-14}$ Rapid throughput and early discharge place additional demands on community resources. ${ }^{15-17}$ In addition, the drive to improve the quality of care in terms of safety, effectiveness and patient experience has been renewed through publication of the Darzi report (2008). ${ }^{18}$ This raises expectations and places further demand on services. Yet recent public inquiries highlight a series of deficiencies in NHS care in general, ${ }^{19}$ and the National Audit Office report identifies deficiencies in trauma care in particular. $^{20}$ Although evidence-based ideal models of trauma care have been described, ${ }^{11}{ }^{20}$ service providers' understanding of trauma patients' needs, their perspectives on real world provision and how services can better meet the needs of patients are largely unknown. We therefore undertook a qualitative study to explore the views of those providing services for injured people on the extent to which services meet patients' needs, to identify gaps in service provision and views on factors contributing to those gaps.

\section{METHOD}

We undertook a qualitative study, nested within a multicentre longitudinal quantitative study, assessing the longer term impact of injuries on physical, psychological, occupational and social functioning in working age adults. ${ }^{21} \mathrm{~A}$ total of 668 adults admitted to acute NHS trusts following an unintentional injury in four study centres (Nottingham, Bristol, Leicester/Loughborough and Surrey) took part in the quantitative part of the study. The qualitative component comprised interviews with a sample of patients participating in the quantitative study, their carers and representative service providers. This article reports on these service provider accounts. The following description of our methodology is guided by 'The Consolidated Criteria for Reporting Qualitative Studies (COREQ) 32 item checklist' to ensure transparency and aid critical appraisal. ${ }^{22}$

A sampling frame for service providers was based on: (1) patient service use reported in self-completed questionnaires at 1,2 and 4 months postinjury (in the main study), (2) an analysis of 22 patient interviews reporting service providers they felt had helped their recovery and (3) the advice of two lay research advisers based on their experiences of recovery from injury (both members of the East Midlands Collaboration for Leadership in Applied Health Research and Care Public Involvement Group who expressed interest in the project). One lay research adviser contributed throughout the study and the other in the preliminary stages only. We created a list of service providers and described the proportion of patients using their service and their frequency of use. We then selected which types of service providers to invite to the study based on the highest proportion and most frequent patient use. In addition, service providers who were less frequently used but consistently described as being helpful (eg, private practitioners such as osteopaths and physiotherapists) were also selected. A quota sample for types of service provider and professional role (manager or more junior) was constructed for each study centre. For hospital-based services, managers of relevant services were approached initially to identify the most appropriate interviewee at a senior level and to forward the invitation to more junior members of staff. A similar approach to recruitment was adopted for non-hospital based service providers. Where there were multiple service providers within a five mile radius of the hospital (GP practices, physiotherapists and osteopaths in private practice), a fixed interval sampling method based on a sampling frame ordered by distance from the hospital was trialled. However, only one GP was recruited using this method. In the other three centres, invitations were sent to all GPs within a 5-mile radius of the hospital. Two private osteopaths were recruited by one centre using the same method. All potential participants were sent an invitation including information about the study aims, objectives and background, and all those who responded agreed to participate and no-one dropped out.

We developed a semistructured interview topic guide, based on a review of the literature and previous use in a similar population. ${ }^{23}$ This topic guide explored the nature of the service offered and its role in postinjury care and support, factors that facilitated or hampered access to and delivery of services, and gaps in overall provision. It was piloted with two interviews in one site, and deemed fit for use after discussion among the research team. Further review after four interviews per site and a regular teleconference between researchers aided consistency of approach. Interviewer and interview characteristics are detailed in table 1.

Interview data were coded using NVivo V.10 qualitative data analysis software and thematically analysed following the method outlined in Braun and Clarke. ${ }^{24}$ The data were reviewed by JB, JS, KB and MB (representing all four study centres) and Sarah Earthy, a study principal investigator, to gain understanding of the key experiences described. This was followed by independent coding of $10 \%$ of the transcripts and development of an initial coding frame through group discussion. This process also permitted discussion of any researcher assumptions or bias. The resultant code frame was used 
Table 1 Interviewers and interview characteristics

\section{Interviewers \\ Which authors conducted the interviews \\ Qualifications}

Occupation at the time of study

\section{Gender \\ Training}

Was the interviewer already known to the study participants?

\section{Interviews \\ Setting
Who was present?
Duration
Audiovisual recording
Consent \\ Confidentiality \\ Transcription \\ Field notes \\ Repeat interviews \\ Post interview contact}

\author{
$\mathrm{BK}, \mathrm{JB}, \mathrm{JS}, \mathrm{KB}$ and $\mathrm{MB}$ \\ BK, JB (PhD), JS (MSc), MB (MA (Cantab)), KB (BSc) \\ $\mathrm{JB}, \mathrm{KB}$ (Registered Nurses)
}

BK: research fellow; JB, JS,KB: research associate, MB: research assistant-all university employees

BK, JS, JB, KB: female; MB: male

All have had training and experience in qualitative research methodology A small number of participants were acquainted with their interviewer through prior involvement in quantitative study recruitment and may have been aware of their interviewers' background

Interviews were carried out in the participant's place of work in a quiet private
space
Participant and interviewer only
Interviews lasted between 30 and 60 min
All interviews were audio recorded with participant consent
Consent was obtained at the time of interview or before if conducted by
telephone
Interviewees were assured of anonymity and confidentiality for themselves and
their organisation
Interviews were centrally transcribed and checked for accuracy by site
researchers
Field notes were recorded following the interview to add context to the analysis
No repeat interviews were deemed necessary
All participants were given contact details for any further thoughts or comments
they wanted to add after the interview

by $\mathrm{BK}, \mathrm{JB}$ and $\mathrm{KB}$ to analyse and organise the data in the remaining transcripts. After the primary coding of all 40 interviews, it was determined that data saturation (the point at which no new evidence is emerging) had been achieved and no additional interviews were required. Further cycles of coding enabled researchers to test the codes assigned, produce broader themes and identify relationships and patterns in the data and any divergent cases. Continuous discussions took place to ensure that discrepancies and disagreements were identified and to refine emerging major and minor themes. Finally, three practising clinicians within the study team were asked to comment on the findings to ensure that they reflected their experience and views and to further test their credibility and transferability.

\section{RESULTS}

We directly invited 542 staff members to participate (including acute trusts/ambulance trusts (163); community/primary care (333); private sector (29); social services (15) and voluntary sector (2)). Sixty one managers were approached who were also asked to invite their staff to participate. The numbers of staff each manager approached is not known, but it is estimated at around 400, making 942 total approaches. Forty interviews were completed with providers of a wide range of services (including NHS staff (37); private practice (2); voluntary sector (1)). Among NHS staff, 30 worked in acute care; four in primary/community care and three in the ambulance service. See box 1 for a brief description of the NHS structure as it relates to this article and trauma services.

In accordance with the study protocol, their age and gender were not recorded; however, by selecting participants

Box 1 UK National Health Service (NHS) structure as it relates to this article and provision of trauma services

Services for injured patients may be provided by:

1. NHS acute, ambulance or care trusts (these are in effect public sector organisations providing services on behalf on the NHS)-providing emergency, acute (secondary) and outpatient care. They also provide some community services.

2. NHS general practitioners (primary care/family physicians)) and allied health professionals who contract services for the NHS through the NHS commissioning board and clinical commissioning groups-providing care in the community after the acute injury.

3. Voluntary sector organisations providing additional services to the NHS.

4. Private practitioners providing supplementary care accessed and paid for by the individual patient.

5. Local authority social services providing social worker or occupational therapist support and means tested personal care.

Trauma care may be shared between settings with separate budgets and provision criteria. 
Table 2 Numbers and types of service providers interviewed by the study centre

\begin{tabular}{|c|c|c|c|c|c|}
\hline Study centre & $\mathbf{A}$ & B & C & D & Total \\
\hline Ambulance service-paramedic & & & & 1 & 1 \\
\hline Ambulance service-manager & & & 1 & 1 & 2 \\
\hline Doctor-general practitioner & & & 2 & 1 & 3 \\
\hline Doctor-junior & & & & 1 & 1 \\
\hline Doctor-registrar & & 1 & & & 1 \\
\hline Doctor-consultant & 1 & & 1 & & 2 \\
\hline Doctor-medical director & & & 1 & & 1 \\
\hline Nurse-primary care & & & 1 & & 1 \\
\hline Nurse-junior & 3 & & 1 & & 4 \\
\hline Nurse-senior/sister & & & 1 & 1 & 2 \\
\hline Nurse-specialist & & 1 & 1 & 1 & 3 \\
\hline Nurse-matron & 2 & & 1 & 1 & 4 \\
\hline Occupational therapist & & 2 & & & 2 \\
\hline Physiotherapist-junior & 1 & & & 1 & 2 \\
\hline Physiotherapist-senior & & & & 3 & 3 \\
\hline Physiotherapist-specialist & & 1 & 2 & & 3 \\
\hline Physiotherapist-manager & & & & 1 & 1 \\
\hline Private practice-osteopath & & & 2 & & 2 \\
\hline Psychologist-specialist & & & 1 & & 1 \\
\hline Voluntary sector-manager & & 1 & & & 1 \\
\hline Total & 7 & 6 & 15 & 12 & 40 \\
\hline
\end{tabular}

from different disciplines and levels of seniority, the sample demographic was broadly representative of NHS staff. ${ }^{25}$ The professional roles of service providers interviewed at each of the four sites are presented in table 2. Efforts to recruit representatives from social services or private physiotherapy were unsuccessful. Study centres are identified only by a randomly assigned letter to maintain anonymity. Between 6 and 15 service providers were interviewed in each site depending on the numbers responding to the call for participants.

Analysis of service provider accounts suggests the coexistence of two distinct models of care: an aspirational or ideal model of care which participants strive towards (and would like to adhere to) and a more haphazard, fragmented model based on the realities of NHS practice. These dominant themes emerged through the process of analysis; participants were not specifically asked to describe ideal and real models of care. Individuals, disciplines and settings differed in which model they felt able to follow, but knowledge of and tensions between these two models permeated all service provider accounts.

\section{Ideal model}

Participants' ideal model of trauma care was timely, integrated and seamless:

- "A multidisciplinary effort of managing the patient... everyone has an input into the care... what this particular patient will need from different professional aspects." (Junior nurse, Centre A)

- Care should be effective, informative and compassionate, and endure throughout the patient's recovery journey:

- "They need the right treatment and...to understand what's happening to them and to be listened to, questions actually answered...they need time." (Specialist nurse, Centre B)

- "Everything from start to finish. So the beginning of the injury when they need resuscitation right through to rehabilitation and ongoing...management." (Specialist nurse, Centre C)

\section{Real model}

Participants' accounts gave many examples where individuals, settings and services met these ideal standards. However, they also acknowledged that the reality of care was sometimes less than ideal, often due to time pressures or gaps in provision:

- "We would like to think that we were aiming to provide a high quality of care in a very timely way... but the reality is probably a bit different to that unfortunately." (Senior nurse, Centre D)

- "Staff don't always have that time to give to the patient...the pressures are on the bed and the staff know it...so you daren't ask (the patient) a question in case you get held up." (Senior nurse, Centre C)

- "Patients aren't getting the right level of rehab that they need...there's a lack of psychological support and vocational rehab, lots of things that in an ideal world these patients should be getting, but they're not." (Physiotherapist, Centre A)

Participants described a complex system in which these two models of practice coexist and give rise to very different standards of care (see table 3).

Participants recognised and managed daily inconsistencies between ideal and real models of care. Their accounts also provide insight into possible reasons for the divergence between models, as described below. 
Table 3 Ideal \& Real Models of Care in relation to Darzi's (2008) ${ }^{18}$ three elements of good quality care

Ideal

Real

Safety

- "Actually they're going to be safe in our hands and ... the care they're going to receive is good." (Senior nurse, Centre D)

- "That's my patient, their safety comes first." (Specialist nurse, Centre B)

- "Being able to provide a service with skilled clinicians ... the knowledge to be able to treat a patient safely ... as an emergency service you can't ask for any more." (Manager ambulance service, Centre C)

\section{Effectiveness}

- "Getting the patients treated at the right time with the right services ... getting them treated early picking up the people that need additional services especially psychology getting them in there quickly to ... prevent future disability." (Occupational therapist, Centre B)

- "My role is to ensure that the patient's care pathway is efficient, timely and they have a satisfaction in the service." (Junior nurse, Centre A)

Patient experience

- "Enough information about their condition to help them not to be scared of it ... they need to understand the reasons why we have asked them to do what they are doing ... to understand what they are feeling and experiencing." (Senior physiotherapist, Centre D)

- "I think when you want to get patients to theatre ... it's full ... sometimes you see a little bit of harm come to patients because they don't get to theatre in time." (Junior doctor, Centre D)

- "So whether or not the continual monitoring gets done is a different matter... without continual monitoring you can't say that they're going to remain fine." (Junior nurse, Centre C)

- "We get a phone call maybe for some pain medication ... somebody's got a major life event and we don't know about it (lack of communication) ... so there are safety issues there about prescribing medication." (GP, Centre D)

- "We have so many ankle fractures sitting around on the ward for a week before the operation... if you operated on them straightaway ... they would be done and out the next day." (Junior doctor, Centre D)

- "It's a high pressure job ... you don't feel like you can give high quality care ... that individual's satisfaction of what you consider high quality care isn't always ... what the department offers." (Senior Nurse, Centre D)

- "I would say...for the patients who need psychological support that's one of the main things that's lacking ....in every hospital ... there's no access to it for patients." (Physiotherapist, Centre A)

- "I suppose it's easier just getting your head down and doing the tasks ... during busy times especially just knowing that you've done this, this and this, ....It's almost like once you've done the task, then it becomes somebody else can care about the kind of emotional side of it." (Junior nurse, Centre C)

\section{Knowledge}

Service providers demonstrated a comprehensive understanding of the potential impact of injury on patients' lives:

- "Injury involves change to a normal routine, the frustration of not being able to do what you feel you ought to...or want to be able to do. The financial strains, the family strains, and the relationship strains...it's endless." (Senior physiotherapist, Centre D)

This knowledge, gained through experience, training and research, informed their ideal model of care:

- "I'll be looking at the impact on their functional activity, their work and leisure, their personal care and the way it impacts on their lives socially and psychosocially as well ... the way it's affecting their, ... family life and relationships." (Occupational therapist, Centre B)

Where there were gaps in knowledge, these related to difficulty keeping fully informed about the range of NHS and other services available:

- "Either I don't know about the services available or it's difficult to access them in a timely fashion...that can be frustrating at many levels." (General Practitioner, Centre D)

\section{Research}

Participants also explicitly referred to research evidence informing best models of care for their professional role:

- "Research suggests that good quality trauma care makes a massive difference to people's outcome overall, is a huge benefit to society...quite apart from being the right thing to do...it's expensive to provide...but on the whole it saves money." (Consultant, Centre C)

- "So if people have got a job open...we intervene very early with education, because it's been found research wise that the earlier that's addressed, the better the outcome." (Occupational therapist, Centre B)

- "Things like complex regional pain syndrome...something that can happen after an injury...picking that up early and dealing with it early the research shows that the outcomes are so much better." (Specialist physiotherapist, Centre D)

Research evidence was also used proactively to demonstrate where care was falling below ideal standards:

- "There are big gaps but hopefully with the information I am gathering I can report ... figures and percentages ... to say they are not meeting these people's services." (Specialist nurse, Centre D) 
Box 2 Possible improvements to care based on service provider's perspectives

Knowledge

- Develop practitioner capacity to utilise and collate evidence relating to standards of care

- Develop an online regularly updated directory of services for practitioner reference

Services

- Expand trauma theatre capacity to ensure appropriately timed surgical intervention

- Expand existing and develop new screening and treatment options for postinjury psychological problems

- Develop capacity for community rehabilitation (residential, domiciliary or outpatient) to ensure early discharge of medically fit patients, sustain progress made in hospital and enable early intervention to prevent longer term problems

Funding streams

- Harmonise referral criteria across geographical boundaries

- Facilitate service access for those who do not fit 'typical' criteria (based on clinical assessment of need)

- Remove incentivised targets for particular cohorts and equalise access based on clinical need

Staffing and skill mix

- Ensure adequate staff numbers to effectively and compassionately meet clinical demands

- Involve senior practitioners in scoping staff and skill mix requirements

- Identify non-clinical tasks and devolve to additional administrative workforce

- Utilise senior clinical expertise to drive improvements in standards through direct clinical input and supervision of junior staff

Patient expectations

- Improve patient information at all levels using a range of sources and means

- Expand public education on appropriate NHS use

- Enhance public involvement in realistic NHS goal setting and resource allocation

Communication and information

- Formalise systems to ensure that outlying patients are not neglected

- Engage practitioner groups in developing initiatives to improve communication between primary and secondary care

- Develop secure means of information sharing with non NHS practitioners

Organisational values and priorities

- Ensure equal focus and resourcing for acute and rehabilitation phases of recovery

- Develop measures and means to collate evidence of longer term injury outcomes, for example, return to work

- Undertake economic research into comparative costs of shortterm intensive multidisciplinary rehabilitation versus long-term disability and resource use

- Ensure that individual clinical need drives care rather than political or organisational targets

- Recognise practitioner expertise and facilitate practice according to their ideal evidence-based model of care

Additional evidence was desired to support improvements in care:

- "We use the DASH (Disabilities of the Arm, Shoulder and Hand) outcome measure...it's got a good evidence base...it incorporates the individual's view of their function...I'd like to look at how we can produce something that reflects that, but also reflects the economical advantage in the long term but...the difficulty is people often are looking at short economical advantage, not long term." (Occupational Therapist, Centre B)

\section{Barriers to delivery of service provider's ideal model of care}

Participant accounts suggest that divergence between ideal and real models of care cannot be accounted for by lack of understanding of the impact of injury or evidence of best models of care. However, they provide clear evidence of factors (variously described as 'gaps', 'blocks' or 'holes') affecting implementation of this knowledge into practice:

- "There's lots of holes for the patient to fall down depending on who has interacted with them in the hospital, what sort of discharge plan they have got." (Specialist physiotherapist, Centre C)

- "There's blocks at every stage of the process...you make all these good plans...but it just doesn't work." (Junior doctor, Centre D)

- "There are massive gaps in the service...for somebody who needs more care and more help...it can clog up the system terribly...for shortage of somewhere for them to go that's a safe environment." (Physiotherapist, Centre D)

Analysis of the interviews suggests six distinct types of 'blocks' 'gaps', or 'holes' impeding service delivery.

\section{Access to services}

Study participants described significant gaps in provision and delays in access to services which hindered recovery for the individual and caused whole system blockages and inappropriate resource use. Particular issues were highlighted in trauma theatre capacity, resources for younger patients, psychological services and community rehabilitation.

- "This week...I have ended up putting 12 incident forms in for patients who haven't gone to theatre within 36 h." (Specialist nurse, Centre D)

- "We run into problems with waiting for social services and packages of care...we've got a patient who's been here for four weeks fit for discharge." (Junior doctor, Centre D)

- "All those long term rehab places...particularly for younger patients...are in very short supply...once they've got over the immediate injury, they need to get on with trying to rehabilitate themselves." (Consultant, Centre C)

- "Some people have had to wait for four to 5 months before starting counselling." (General Practitioner, Centre C)

- "If they need physio in their own home, the wait for an urgent referral is 18 weeks...if we've worked really hard (in hospital) and got them to a really good 
point...that generates a lot of frustration....and we can't do anything about it." (Specialist physiotherapist, Centre D)

Lack of available psychological support for patients was noted by many participants who described a combination of strategies to manage patients' psychological needs (avoidance, amateur psychology or referral to a general practitioner). Some disciplines such as physiotherapy provided extensive psychological support in the absence of formal or 'standardised' psychological services. However, there was general concern at how a lack of more formal specialist support might affect rehabilitation:

- "We see people who've had quite horrendous experiences...they're making a physical recovery. But when they talk about what's happened...the people that you think are fine sometimes just break down...it would be great if there was someone you could just call and say '...I've got a patient I think you need to see', but that isn't available to us." (Occupational therapist, Centre B)

- 'I don't think we address the psychological aspect at all...and that would help our patient because if they're in the right frame of mind it will definitely improve their input into...their physio and that sort of thing." (Doctor/Registrar, Centre B)

\section{Funding streams}

Interviewees referred to further blockages caused by funding streams and restrictive access to services. This prevented referral of patients based on individual need and created ethical dilemmas for service providers.

- Patients with minor head injuries "get followed up, hopefully, but only if they live within (city)...the rest of them are left to their own devices." (Matron, Centre C)

- "I saw a 40 year old chap today...lives on his own but he didn't really hit the right criteria for...social support." (Senior physiotherapist, Centre D)

- "It becomes slightly unethical if you've fractured a few centimetres below (the neck of femur)... you suddenly don't fall into the same category...you don't have the same time pressure and you won't have the same treatment afterwards." (Consultant, Centre A)

- "You've got different pathways for the different areas and that can be really frustrating...we can send somebody home non-weight bearing....and they'll have to wait 12 weeks for a physiotherapist." (Specialist nurse, Centre B)

\section{Staffing and skill mix}

Service providers described not only lack of staff per se as having a profound effect on service delivery, but also reductions in the level of expertise through inadequate 'skill mixing' and excessive administrative or managerial demands on senior practitioners (which reduced the potential for improvements in quality of care). There was also a perception that external review of staffing underestimated clinical demands on staff with resultant recommendations impacting on the quality of care.

- “Today I've visited probably 9 wards by eight o'clock this morning and all of those wards were helping each other out because they were short staffed." (Matron, Centre A)

- "Things like intravenous pain relief are delayed... that's ethically wrong to delay pain relief just because a service had put on the wrong skill mix." (Paramedic, Centre D)

- "There's this kind of pressure to downgrade posts...to reduce the level of expertise." (Physiotherapists, Centre C)

- "There's just so many things you don't need to be a nurse to do. I don't need to be a qualified nurse to tick a few audits...if some of those things were taken off me I would be able to support the team better on the ward and the patients better." (Matron, Centre D)

- "The trust asked for an external review on the nursing figures on the wards...it completely underestimated the patients with dementia, the patients that came in with very poor nutritional states...that was a massive battle and we went to a very low place in terms of nursing care." (Matron, Centre A)

\section{Patient expectations, changing demographic and NHS use}

Participants felt some patients had unrealistic expectations of recovery and made inappropriate use of hospital services against a backdrop of increasing demands from an ageing population:

- "There's a sort of expectation that we can just click our fingers and put a few bits of metal in and...there you are, you're back to normal...we are not magicians, we can't turn everything back to how it was before." (Consultant, Centre A)

- "One in four people don't need to be in ED (Emergency department). We have a high level of inappropriate use." (Junior nurse, Centre C)

- "The mix has changed...we are predominantly... elderly care patients with acute confusion, with dementia, and trauma...it is very heavy...patients are highly dependent." (Specialist nurse, Centre D)

\section{Communication and information}

Service providers acknowledged that communication between services and settings is sometimes poor and compounded by professional boundaries and hierarchy. The complexity and demands of service provision also make effective communication with patients and between professionals increasingly difficult.

- "For the outlying wards, the doctors will present the patients, they won't...necessarily know where they are in the hospital, they might be moved around here, there and everywhere...they may miss a patient on an outlying ward." (Physiotherapist, Centre A)

- "We need better working relationship with the community; the community needs to have better working 
relationship with us. We don't have that contact at all." (Matron, Centre D)

- "I don't have access to notes...because we (private osteopath) are on the cusp of the NHS...it prevents me from doing something, treatment wise, technique wise...all these expensive tests...but the person that could potentially help the patient can't get hold of them." (Private osteopath, Centre C).

\section{Organisational values and priorities}

Study participants described significant tensions between their professional and personal views on the care that should be provided and organisational values and political and financial priorities which could lead to an emphasis on short-term finite outcomes:

- "For society and for the patient longer term outcomes are hugely important. To my view there's a disconnect...because services at an earlier stage...don't have a financial interest in the longer term outcome. They only have an interest in the outcome of that phase." (Physiotherapist, Centre C)

- "We have these very sort of...politically driven clinical guidelines." (Consultant, Centre A)

- "I think they don't actually collect...outcomes long enough in my view." (General Practitioner, Centre C)

Some service providers took a more proactive stance in seeking to influence the commissioning of services or in resisting management led pressures:

- "We need to get our commissioners to understand where the gaps are and what the problems are...to get them to wake up...these patients aren't getting the right level of rehab they need." (Physiotherapist, Centre A)

- "I feel under pressure to follow the alternative care pathways, but I'll only do that if it's appropriate, I won't do it because I'm supposed to." (Paramedic, Centre D)

- "I do go against management; I will not discharge somebody until I know (it) will be safe regardless of the pressure on beds." (Specialist nurse, Centre B)

\section{DISCUSSION}

Our participants gave accounts of an "ideal" model of care which demonstrate a clear knowledge of and commitment to Darzi's (2008) ${ }^{18}$ elements of high quality care and key components of trauma provision. ${ }^{11} 20$ However, service providers reported that their ability to adhere to this model in practice was at times compromised and their clinical decisions limited by factors such as insufficient resources, gaps in communication and information, conflicting organisational values and priorities, unrealistic patient expectations, demands of an ageing population and inadequate staffing levels or skill mix. Our participants' accounts suggest that basic quality standards of safety, efficacy and patient experience may not be universally met by the current provision. Within the "real" model of care, service providers cannot always respond to the full range of patient needs following injury or anticipate predictable sequelae such as psychological distress. Service providers are fully aware of these limitations and consequences and strive to deliver the best care they can within increasingly limited resources, downgraded skill mix and complex systems. However, the risk for patients is that this may result in fragmented, inequitable and suboptimal care.

Our study draws on the views of a wide range of service providers in secondary and primary care from four areas serving varied populations in terms of size, ethnic and socioeconomic mix. While our findings cannot be generalised to all UK primary and secondary care settings, it is unlikely that the experiences of the service providers interviewed are restricted to the four study centres only. Conduct of the interviews and analysis by researchers with diverse academic and clinical backgrounds also enhanced the validity and transferability of the findings. Sample selection based on patients' accounts of the services used resulted in a combination of perspectives from frequently accessed services and those accessed by fewer patients with specific needs. We had difficulty in recruiting some types of service providers, notably social services, counselling services and physiotherapists working in private practice. However, these services were rarely accessed by the impact of injuries study (IOIS) patients. Respondents in some staff groups were identified by their managers, who may have chosen people who held particular views. However, the diverse positive and negative views provided by service providers would suggest that this is unlikely to have had a large impact on our findings. Since all participants conveyed positive and negative views, there were no divergent cases (in which a wholly positive or negative model was described); however, the proportion of positive vs negative views varied between participants and disciplines. Future analysis could expand on this to identify factors sustaining ideal care and analysis of IOIS patients and carer data will permit comparison with their experiences of care.

This study contributes to current debate on the quality of NHS care, illustrating how service provider perspectives can improve our understanding of the current situation and inform future improvement. Successive studies show how the gap between "ideal" and "real" models of care can affect service provider well-being and caring, ${ }^{26} 27$ and this study demonstrates this process in action. The recently published 'RN4CAST study' of hospitals in 300 European countries goes further and demonstrates how a reduction in nursing numbers and skill mix alone can be associated with poorer outcomes and higher mortality rates. ${ }^{28}$ This study also contributes to possible solutions; practitioner knowledge of local context is increasingly acknowledged as essential to overcome barriers to translating evidence into practice. ${ }^{29}$ While many studies identify means to improve the effectiveness and safety of care, this study adds to an understanding of the 'aesthetics of experience' or how services 
feel (their usability and emotional content). ${ }^{30}$ These are also important determinants of best practice and patient experience and can lead to improvements in service delivery and patient care. ${ }^{30}$

This study questions current media and policy debate exhorting service providers to be more compassionate, 183132 to extend their knowledge and education ${ }^{18} 33$ and to work harder to raise standards, ${ }^{34}$ and provides alternative perspectives on factors impeding an ideal model of care. It suggests that compassion is not lacking and that service providers (across a wide range of disciplines) not only have a comprehensive understanding of the impact of injury on patients' lives, but also have knowledge of evidence identifying best models of care. While it is often considered that experiential rather than research knowledge underpins practice, many participants demonstrated familiarity with current research and awareness of the role of scientific evidence in improving standards. However, the extent to which their understanding and knowledge informs practice is determined by factors which are frequently beyond their control. Some services, settings and individuals clearly feel their context of care is more conducive to practice according to an ideal model than others; for example, striking differences exist between nursing and physiotherapy care postinjury. ${ }^{35}$ Service providers' experiences of providing care; which they feel is at odds with their ideal model of care, give rise to a series of practical suggestions for service improvements. These wide-ranging suggestions described in box 2 are based on recommendations elicited through participant interviews and extrapolation from the data. However, the following three priorities were most frequently identified: improving psychological screening and support, reduction in theatre delay and improving access to early adequate physiotherapy. Further research combining scientific evidence of the impact of injury with practitioner knowledge of local context may assist in clarifying future priorities for action. ${ }^{36}$

Improving planning and organisation of trauma care can achieve better treatments and improved outcomes. ${ }^{37}$ The views of a range of service providers across the trauma pathway are important; they demonstrate compassion, a comprehensive understanding of patients' needs, knowledge of the evidence base underpinning best practice and motivation to deliver the best possible care. Service provider views should be routinely used to inform service design, planning and delivery, and the impact of this on the quality of care, patient outcomes and patient experience should be evaluated in future research. However, service provider views are only one side of the story; the views of patients and carers also need to be collected, listened to and acted on.

\footnotetext{
Author affiliations

${ }^{1}$ University of the West of England, Research and Innovation, University Hospitals Bristol NHS Foundation Trust, Education Centre, Bristol, UK ${ }^{2}$ Department of Sociology, Faculty of Arts and Human Sciences, University of Surrey, Guildford, Surrey, UK

${ }^{3}$ Loughborough Design School, Loughborough, UK

${ }^{4}$ Division of Primary Care, School of Medicine, Nottingham University,

University Park, Nottingham, UK
}

${ }^{5}$ Nottingham University Business School, Nottingham, UK

${ }^{6}$ Nottingham University Hospitals, Nottingham, UK

${ }^{7}$ DREEAM (Department of Research and Education in Emergency medicine, Acute Medicine and Major Trauma), Nottingham University Hospitals NHS

Trust, Nottingham, UK

${ }^{8}$ Department of Emergency, Bristol Royal Infirmary, Bristol, UK

${ }^{9}$ Division of Primary Care, School of Medicine, University Park,

Nottingham, UK

Contributors DK, JS, FC, JB and BK made substantial contributions to the conception and design of the work, KB, SE, JS, JB, BK, MB and GE made substantial contributions to the acquisition and analysis of the data; $K B, S E$, $\mathrm{MB}, \mathrm{JS}, \mathrm{JB}, \mathrm{BK}, \mathrm{JC}$ and DK contributed substantially to the interpretation. All authors contributed to the drafting of the work, its critical revision and approved the final version to be published.

Funding This research was funded by the National Institute for Health Research Collaboration for Leadership in Applied Health Research and Care for Nottinghamshire, Derbyshire and Lincolnshire (NIHR CLAHRC NDL). The views expressed in this work are those of the authors and not necessarily those of the NHS, the NIHR or the Department of Health.

\section{Competing interests None.}

Patient consent Obtained

Ethics approval Ethical approval for the study was provided by Nottingham Research Ethics Committee 1 (number: 09/H0407/29).

Provenance and peer review Not commissioned; externally peer reviewed.

Data sharing statement No additional data are available.

Open Access This is an Open Access article distributed in accordance with the Creative Commons Attribution Non Commercial (CC BY-NC 4.0) license, which permits others to distribute, remix, adapt, build upon this work noncommercially, and license their derivative works on different terms, provided the original work is properly cited and the use is non-commercial. See: http:// creativecommons.org/licenses/by-nc/4.0/

\section{REFERENCES}

1. Office for National Statistics: Mortality statistics: Deaths registered in 2011 (Series DR) Table 5. http://www.ons.gov.uk/ons/publications/ re-reference-tables.html?edition=tcm\%3A77-277727 (accessed 11 Feb 2014).

2. Department of Health. HES online: Hospital Episode Statistics. External cause table 2011-2012. http://www.hscic.gov.uk/ searchcatalogue productid $=9161 \& q=$ title $\% 3 a \% 22$ Hospital+Episode +Statistics\%3a+Admitted+patient+care\%22\&pubdate $=\%$ 2 c2012\&sort=Relevance\&size $=10 \&$ page $=1 \#$ top $($ accessed 11 Feb 2014).

3. Department for Trade and Industry. 24th (final) report of the home and leisure accident surveillance system, 2000, 2001 and 2002 data. http://www.hassandlass.org.uk/reports/2000_2002.pdf (accessed 11 Feb 2014)

4. Office for National Statistics. Mortality statistics. Injury and Poisoning Series DH4 no 30. 2005. http://www.ons.gov.uk/ons/rel/vsob1/ mortality-statistics--injury-and-poisoning--england-and-wales-series-dh4--discontinued-/no--30-2007/index.html (accessed 11 Feb 2014).

5. Department of Health. Hospital Episode Statistics. External cause table 2006-07. http://www.hscic.gov.uk/catalogue/PUB02533/ hosp-epis-stat-admi-ext-caus-06-07-tab.xIs (accessed 11 Feb 2014)

6. Lyons RA, Kendrick D, Towner EM, et al. Measuring the population burden of injuries-implications for global and national Estimates: a multi-centre prospective UK longitudinal study. PLOS Med 2011;8 (12). http://www.plosmedicine.org/article/info\%3Adoi\%2F10.1371\% 2Fjournal.pmed.1001140 (accessed 6 Apr 2014).

7. Polinder $\mathrm{S}$, Haagsma J, Belt E, et al. A systematic review of studies measuring health-related quality of life of general injury populations. BMC Public Health 2010;10:783.

8. Black J, Herbison G, Lyons R, et al. Recovery after injury: an individual patient data meta-analysis of general health status using the EQ-5D. J Trauma 2011;71:1003-10.

9. Wiseman T, Foster K, Curtis K. Mental health following traumatic physical injury: an integrative literature review. Injury 2013;44:1383-90. 
10. O'Donnell M, Bryant R, Creamer M, et al. Mental health following traumatic Injury: toward a health system model of early psychological intervention. Clin Psychol Rev 2008;28:387-406.

11. NHS Confederation \& Ambulance Service Network. Implementing trauma systems: key issues for the NHS. 2010. http://www. nhsconfed.org/Publications/Documents/Implementing_trauma_ systems_report.pdf (accessed 28 Apr 2014).

12. The intercollegiate group on trauma standards. Regional trauma systems interim guidance for commissioners. London: The Royal College of Surgeons of England, 2009.

13. Centre for Workforce Intelligence. Regional trauma networks: NHS clinical advisory group on trauma workforce. London: CFWI Regional Trauma Network Team, 2011.

14. Health \& Social Care information Centre. Focus on Accident \& Emergency, December 2013. http://www.hscic.gov.uk/catalogue/ PUB13040/acci-emer-focu-on-2013-rep-V2.pdf (accessed 28 Feb 2014).

15. Department of Health DH-TCS Programme. Transforming Community Services: ambition, action, achievement: Transforming Rehabilitation Services. 2009. http://lx.iriss.org.uk/sites/default/files/ resources/DH_101420.pdf (accessed 28 Feb 2014).

16. NHS Confederation. Transforming local care: Community Healthcare rises to the Challenge. Community Health Services Forum Briefing; 2013, 258 http://www.nhsconfed.org/Publications/Documents/ Transforming-local-care.pdf (accessed 28 Feb 2014).

17. Edwards N. Community services; how they can transform care. The Kings Fund, 2014. http://www.kingsfund.org.uk/sites/files/kf/field/ field_publication_file/community-services-nigel-edwards-feb14.pdf (accessed 28 Feb 2014).

18. Department of Health. High quality care for all NHS next stage review. 2008. http://webarchive.nationalarchives.gov.uk/ 20130107105354/http://www.dh.gov.uk/prod_consum_dh/groups/dh_ digitalassets/@dh/@en/documents/digitalasset/dh_085828.pdf (accessed 16 Feb 2014).

19. Francis R. Report of the Mid Staffordshire NHS Foundation Trust Public Inquiry. London: The stationery office, 2013. http://www. midstaffspublicinquiry.com/report (accessed 16 Feb 2014).

20. The National Audit Office. Major trauma care in England; Report by the Comptroller and Auditor General. 2010. http://www.nao.org.uk/ report/major-trauma-care-in-england/ (accessed 16 Feb 2014).

21. Kendrick D, O'Brien C, Christie N, et al. The impact of injuries study. Multicentre study assessing physical, psychological, social and occupational functioning post injury-a protocol. BMC Public Health 2011:11:963.

22. Tong A, Sainsbury P, Craig J. Consolidated criteria for reporting qualitative research (COREQ): a 32 -item checklist for interviews and focus groups. Int J Qual Health C 2007;19:349-57.
23. Sleney J, Christe N, Earthy S, et al. Improving recovery-learning from patients experiences after injury: a qualitative study. Injury 2014;45:312-19.

24. Braun V, Clarke V. Using thematic analysis in psychology. Qual Res Psychol 2006;3:77-101.

25. NHS: The Information Centre for health \& social care. NHS Workforce: Summary of staff in the NHS: Results from September 2012 Census Published online. http://www.hscic.gov.uk/catalogue/PUB10394/ nhs-staf-2002-2012-over-rep.pdf (accessed 06 Apr 2014).

26. Glasberg A, Eriksson S, Norberg A. Burnout and 'stress of conscience' among healthcare personnel. J Adv Nurs 2007:57:392-403.

27. Juthberg C, Eriksson S, Norberg A, et al. Perceptions of conscience, stress of conscience and burnout among nursing staff in residential elder care. J Adv Nurs 2010;66:1708-18.

28. Aiken L, Sloane D, Bruyneel L, et al. for the RN4CAST consortium. Nurse staffing and education and hospital mortality in nine European countries: a retrospective observational study. Lancet 2014;383:1824-30. http://dx.doi.org/10.1016/S0140-6736(13) 62631-8 (accessed 03 Mar 2014).

29. Flottorp S, Oxman Al, Krause J, et al. A checklist for identifying determinants of practice: a systematic review and synthesis of frameworks and taxonomies of factors that prevent or enable improvements in healthcare professional practice. Implement Sci 2013;8:35. http://www.implementationscience.com/content/8/1/35

30. Bate $\mathrm{P}$, Robert $\mathrm{G}$. Bringing user experience to healthcare improvement: the concepts, methods and practices of experience based design. Oxford\& New York: Radcliffe Publishing, 2007.

31. Department of Health: NHS Commissioning Board. Compassion in practice: Nursing Midwifery and care staff our vision and strategy. 2012. http://www.england.nhs.uk/nursingvision/ (accessed 11 Feb 2014).

32. BBC Report: Nurses in drive for more 'compassionate care'. 2012. http://www.bbc.co.uk/news/health-20583115 (accessed 28 Feb 2014).

33. Adams S, Smith R. Report: Nurses 'are losing their sense of compassion'. The Telegraph 2012 Jan 09. http://www.telegraph.co. uk/health/healthnews/9003772/Nurses-are-losing-their-sense-ofcompassion.html (accessed 16 Feb 2014).

34. Royal college of Nursing. Special report: Frontline First: Running the red light. 2013. http://royalnursing.3cdn.net/e678a38646d8d670b1 rdm6bgu19.pdf (accessed 16 Feb 2014).

35. Beckett K. Professional wellbeing and caring: exploring a complex relationship. Br J Nurs 2013;22:1118-24.

36. Brussoni M, Towner E, Hayes M. Evidence into practice: combining the art and science of injury prevention. Inj Prev 2006;12:373-7.

37. World Health Organisation. Guidelines for essential trauma care. 2004. http://whqlibdoc.who.int/publications/2004/9241546409.pdf (accessed 28 Feb 2014). 